\title{
Anti-corrosive Properties of New Eco-friendly Dimethylamino Compounds on C- steel Corrosion in $2 \mathrm{M} \mathrm{HCl}$
}

\author{
A.M. Eldesoky ${ }^{1}$, M.A. Diab ${ }^{2, *}$, A.Z. El-Sonbati ${ }^{2}$ and S.F.Salam ${ }^{2}$ \\ ${ }^{1}$ Engineering Chemistry Department, High Institute of Engineering \&Technology (New Damietta), \\ Egypt and Al-Qunfudah Center for Scientific Research (QCSR), Chemistry Department, Al-Qunfudah \\ University College, Umm Al-Qura University, KSA. \\ ${ }^{2}$ Chemistry Department, Faculty of Science, Damietta University, Damietta 34517, Egypt. \\ *E-mail: $\underline{\text { m.adiab@yahoo.com }}$
}

doi: $10.20964 / 2017.05 .73$

Received: 29 January 2017 / Accepted: 11 April 2017 / Published: 12 April 2017

\begin{abstract}
The inhibitive effect of new eco-friendly dimethylamino compounds, named (2E,4E)-5-(4(Dimethylamino)phenyl)-1-(pyridin-2-yl)penta-2,4-dien-1-one (Compound (I )) and (E)-1-(Anthracen10-yl)-3-(4-(dimethylamino)phenyl)prop-2-en-1-one (Compound (II)) versus CS and its adsorption habit were obtain in $2 \mathrm{M} \mathrm{HCl}$ solution utilized Weight loss, TP, (EIS) and (EFM) techniques. The outcome obtain from IE improve with the raising the inhibitor dose. The \%IE orders of organic compound are follow: Compound (II) > Compound (I). Kinetic activation parameters such as activation energy, entropy and enthalpy of activation were obtained from the influence of temperature on inhibition and corrosion. The types of new eco-friendly dimethylamino compounds are mixed kind inhibitor whose adsorption found by isotherm Temkin. EIS diagrams show that adsorption of new ecofriendly dimethylamino compounds increases the transfer resistance and decrease the capacitance of interface metal/solution. The morphology of inhibited CS was evaluated by SEM and EDX. Relation among calculations of quantum chemical and protection efficiency of the investigated assembled is confirmed by utilized the Density Functional Theory (DFT). Molecular docking was utilized to predict the binding among new eco-friendly dimethylamino compounds and the receptor of breast cancer mutant 3hb5-oxidoreductase.
\end{abstract}

Keywords: Eco-friendly, Adsorption, C-steel, SEM-EDX, Molecular docking.

\section{$\underline{\text { FULL TEXT }}$}

(C) 2017 The Authors. Published by ESG (www.electrochemsci.org). This article is an open access article distributed under the terms and conditions of the Creative Commons Attribution license (http://creativecommons.org/licenses/by/4.0/). 